\title{
Al-Maghazi /The Expeditions
}

DOI 10.18196/AIIJIS.2018.0083.128-132

\section{MUHAMMAD AFFAN}

Mahasiswa Pascasarjana Universitas Islam Negeri Sunan Gunung Djati

$\begin{array}{ll}\text { Judul } & : \text { The Expeditions } \\ \text { Judul Asli } & : \text { Al-M aghazi } \\ \text { Penulis } & : \text { M a'mar ibn Rasyid } \\ \text { Penerjemah } & : \text { Sean W. Anthony } \\ \text { Penerbit } & : \text { N ew York U niversity Press } \\ \text { Kota } & : \text { New York } \\ \text { Tahun } & : 2015 \\ \text { Halaman } & : x l i x+274 \\ \text { ISBN } & : 978-1-4798-1682-8\end{array}$

Buku The Expeditions: An Early Biography of M uhammad pada dasarnya adalah kitab al-Maghazi yang ditulis oleh Ma'mar ibn Rasyid. Sebagaimana sub-judulnya yang bermakna sebuah biografi awal Nabi M uhammad SAW, kemunculan buku ini potensial mengejutkan bagi banyak peminat sejarah Nabi Muhammad SAW. Hal ini disebabkan karena secara umum, para peminat sejarah Nabi Muhammad SAW lebih mengenal kitab sirah nabawiyah Ibnu Ishaq, al-M aghazi al-Waqidi, maupun Thabaqat al-kubra Ibnu Sa'ad sebagai sumber sejarah Nabi SAW terawal yang masih dapat dibaca dewasa ini.

Buku-buku sejarah Nabi SAW yang kontemporer biasanya juga tidak mencantumkan al-Maghazi karya Ma'mar ibn Rasyid sebagai salah satu sumber rujukan. Hal ini juga yang menyebabkan al-Maghazinya Ma'mar ibn Rasyid tidak begitu dikenal oleh para peminat sejarah Nabi M uhammad SAW. Oleh sebab itu, diterbitkannya The Expeditions oleh New York University Press menjadi sebuah momentum untuk mengenali kitab ini sekaligus menambah referensi sejarah Nabi M uhammad SAW dari sumber yang terawal.

The Expeditions yang diterjemahkan kedalam bahasa Inggris oleh Sean W. Anthony ini, diberi kata pengantar oleh M.A.S Abdel Haleem, seorang 
guru besar pada School of Oriental and African Studies, University of London. Dalam edisi Bahasa Inggris ini, ada beberapa tulisan tambahan yang diberikan dengan tujuan untuk memudahkan para pembaca dalam memahami isi al-Maghazi Ma'mar ibn Rasyid. Sehingga, setelah kata pengantar, para pembaca akan disuguhi sebuah pendahuluan yang berisi biografi singkat M a'mar ibn Rasyid, catatan penerjemahan, sebuah rantai kronologis dan juga dua buah peta Jazirah Arab yang memvisualisasikan kondisi Arabia di masa Nabi Muhammad SAW. Semuanya dilengkapi dengan catatan akhir yang disajikan setelah dua halaman peta Jazirah Arab.

Setelah tulisan tambahan tersebut, kitab al-Maghazi baru disajikan kepada pembaca dalam 166 halaman yang terbagi atas 31 bab pembahasan. Pembahasan dimulai dengan kisah penggalian sumur zam zam, lalu kemudian meloncat langsung ke ekspedisi Hudaybiyah, kemudian kembali pada insiden pertempuran di Badar beserta kisah mengenai tawanan di dalamnya. Setelah itu M a'mar ibn Rasyid membahas mengenai syahidnya beberapa sahabat di ar-Raji' yang melibatkan Bani Hudhail.

Ma'mar Ibn Rashid membahas mengenai Bani Nadhir yang diusir oleh Nabi Muhammad SAW dari Madinah karena mengkhianati perjanjian. Selepas itu, Ma'mar ibn Rasyid mengulas insiden di Uhud, perang Ahzab, dan Perang Khaibar. Penulis lalu mendiskusikan perang Uhud, Ahzab dan Khaibar secara kronologis. Selain itu, dia juga mengulas tentang Fath alMakkah, pertempuran Hunain, peristiwa hijrah ke Abysinia, Perang Tabuk, dan orang-orang Aus dan Khazraj yang berlomba-lomba dalam membantu Nabi M uhammad SAW.

Penulis juga membahas mengenai Ashabul Kahfi, kisah pembangunan Masjid Jerusalem oleh Nabi Sulaiman A.S, dan proses wafatnya Nabi Muhammad SAW. Tidak hanya itu, Ma'mar ibn Rasyid juga mendiskusikan suksesi dan peristiwa-peristiwa penting pada masa Khulafa' ar-Rasyidin. Dari kisah pengangkatan Abu Bakar, suksesi dari Abu Bakar kepada Umar Ibn Khattab, pembunuhan Umar, perseteruan Ali dengan Mu'awiyah, sampai penaklukkan Qadisiyah yang menandakan kehancuran kekaisaran Persia.

Dari uraian singkat mengenai bab per bab pembahasan dalam alMaghazi, diketahui bahwa Ma'mar ibn Rasyid tidak menyusun kitab alMaghazi secara kronologis. Akibatnya akan ditemukan kisah yang meloncat-loncat dan tidak seperti satu kesatuan. Selain itu, kitab ini juga 
tidak memfokuskan pembahasan pada satu tema. M eski judul dari kitab ini adalah al-Maghazi, namun pembaca masih akan menemukan banyak kisah yang tidak berhubungan dengan peperangan.

Batasan temporal al-Maghazi Ma'mar ibn Rasyid juga tidak hanya mencakup masa Nabi Muhammad SAW, melainkan juga meliputi masa Khulafah ar-Rasyidin, dan juga kisah sebelum kedatangan Nabi M uhamamd SAW. Hal ini dapat dilihat pada kisah mengenai Nasrani Najran, pembangunan M asjid di Jerusalem oleh Nabi Sulaiman, dan kisah Ashabul Kahfi. Untuk para pembaca yang tidak familiar dengan kitab ataupun buku dari era klasik, al-Maghazi terasa cukup sulit untuk dipahami.

Kitab ini pada dasarnya lebih menekankan pada kekuatan periwayatannya. Oleh sebab itu, para pembaca akan melihat sanad yang jelas pada tiap kisah yang disampaikan. M etode sanad dalam penulisan kitab ini, menjadikannya sebagai kitab hadits tematis yang pembahasannya terutama mengenai peperangan di masa Nabi SAW dan para sahabat.

Tiga figur penting dalam tersusunnya kitab al-Maghazi adalah Ibnu Syihab az Zuhri dari Madinah yang merupakan guru dari Ma'mar ibn Rasyid sendiri. Figur kedua adalah Ma'mar ibn Rasyid sendiri sebagai penulis alMaghazi, dan yang ketiga adalah muridnya Abdul Razaq Ibn Hammam as-San'ani. Peran Abdul Razaq ibn Hammam as-San'ani dalam kitab ini adalah menuliskan apa yang Ma'mar ibn Rasyid ajarkan, yang sumbersumbernya berasal dari gurunya az-Zuhri. Sehingga tidak berlebihan jika Abdul Razaq as-San'ani disebut sebagai tokoh yang menyusun dan menyunting al-M aghazi ini menjadi berbentuk sebuah kitab atas otoritas dari gurunya.

Berbeda dengan Sirah Nabawiyah Ibn Ishaq yang memasukkan syairsyair Arab klasik dalam pembahasannya mengenai sejarah $\mathrm{Nabi}$ Muhammad SAW. Ma'mar ibn Rasyid sepenuhnya bersandar pada periwayatan dari gurunya az-Zuhri. Sehingga, substansi dari kitab AlMaghazi secara umum berasal dari al-Maghazi karya az-Zuhri. Metode sanad ini juga yang menjadi salah satu alasan mengapa Imam Malik dan Imam Ahmad Ibn Hanbal memuji Ma'mar dan mempercayai periwayatan darinya. Jika dibandingkan dengan Sirah Nabawiyah Ibnu Ishaq, al-M aghazi karya Ma'mar ibn Rasyid memang lebih ramping dan ringkas. Sirah Nabawiyah Ibnu Ishaq yang jumlah halamannya berkisar 1380 halaman memang jauh lebih terstruktur, lebih detil, dan kronologis. Sementara alMaghazi yang pembahasannya hanya sekitar 166 halaman menyajikan 
sejarah Nabi Muhammad SAW secara substansial saja. Namun, kualitas sumber periwayatannya menjadi kekuatan yang menutupi kekurangan dalam pembahasan sejarahnya yang ringkas dan sederhana.

Sebagaimana diketahui bersama, sumber tertulis mengenai sejarah Nabi Muhammad SAW tidak ada yang ditulis semasa Nabi Muhammad SAW masih hidup. Tulisan paling awal mengenai sejarah Nabi M uhammad SAW diperkirakan baru dibuat pada masa tabi'in yang salah satunya adalah Aban ibn Utsman ibn Affan yang hidup pada sekitar abad pertama Hijriah. Namun, kitab sejarah Nabi Muhamamd SAW dari abad pertama Hijriah, tidak sampai kepada generasi abad 16 Hijriah dalam keadaan utuh. Dengan kata lain, generasi sekarang tidak dapat lagi mengakses kitab sejarah Nabi Muhammad SAW dari abad pertama Hijriah.

Adapun yang masih dapat di baca dan diteliti sampai masa sekarang antara lain adalah Sirah Nabawiyah Ibnu Ishaq yang berasal dari abad kedua Hijriah. Kemudian dari abad ketiga Hijriah terdapat al-M aghazi karya al-Waqidi serta Tabaqat al-Kubra karya Ibnu Sa'ad. Ketika al-Maghazi Ma'mar ibn Rasyid berhasil disunting dan diproduksi kembali menjadi buku, maka karya ini merupakan sebuah sumber sejarah yang sangat penting dalam kajian sejarah Nabi M uhammad SAW dan para sahabat.

Fakta bahwa Ma'mar ibn Rasyid hidup pada abad kedua hijrah, menjadikan karya ini sebagai sumber sejarah yang sezaman dengan Sirah Nabawiyah Ibnu Ishaq. Hal ini juga berarti bahwa al-Maghazi Ma'mar ibn Rasyid merupakan satu dari dua kitab sejarah yang paling mendekati masa hidup Nabi Muhammad SAW. Sehingga tidak berlebihan jika sub judul dalam edisi alih bahasa Inggris-nya ditulis sebagai an early biography of Muhammad.

Kenyataan bahwa M a'mar ibn Rasyid adalah seorang murid dari Ibnu Syihab az-Zuhri, sebagaimana Ibnu Ishaq juga merupakan murid dari azZuhri, menjadikan al-Maghazi Ma'mar ibn Rasyid sebagai sebuah sumber yang saling melengkapi dengan Sirah Nabawiyah Ibnu Ishaq. Al-Maghazi Ma'mar ibn Rasyid juga dapat menjadi alat pembanding dan kritik pada kisah-kisah sejarah yang diriwayatkan dalam sirah nabawiyah Ibnu Ishaq. Dengan demikian, penelitian-penelitian sejarah Nabi Muhammad SAW dapat menjadi lebih kaya data, kritis dan analitis dengan hadirnya alMaghazi Ma'mar ibn Rasyid secara utuh.

Dengan semua kelebihan dan kekurangan dari al-Maghazi Ma'mar ibn Rasyid, karya ini pantas untuk dijadikan sebagai salah satu sumber 
rujukan utama dalam penelitian-penelitian sejarah Nabi Muhammad SAW. Metode penyajian sejarahnya yang bersanad, ringkas dan substansial adalah sebuah bahan mentah yang sangat berguna dalam penelitianpenelitian sejarah Nabi M uhammad SAW di era modern yang telah bersifat kritis, analitis dan tematis. M engingat bahwa karya ini cukup penting dalam pengembangan ilmu pengetahuan keislaman, menjadi penting untuk di alih bahasakan ke dalam bahasa Indonesia untuk membantu para pelajar muslim di kawasan Asia Tenggara yang kesulitan dalam Bahasa Arab dan Bahasa Inggris agar dapat ikut membaca dan mengkajinya. 